\title{
Norepinephrine Induces PTSD-Like Memory Impairments via Regulation of the $\beta$-Adrenoceptor-cAMP/PKA and CaMK II/PKC Systems in the Basolateral Amygdala
}

\author{
Xiang-Hui Liu ${ }^{1 \dagger}$, Rong-Ting Zhu ${ }^{1 \dagger}$, Bo Hao ${ }^{1}$, Yan-Wei Shi ${ }^{1,2,3}$, Xiao-Guang Wang ${ }^{1,2,3}$, \\ Li Xue ${ }^{1,2,3 *}$ and Hu Zhao ${ }^{1,2,3 *}$ \\ ${ }^{1}$ Faculty of Forensic Medicine, Zhongshan School of Medicine, Sun Yat-sen University, Guangzhou, China, ${ }^{2}$ Guangdong \\ Province Key Laboratory of Brain Function and Disease, Zhongshan School of Medicine, Sun Yat-sen University, Guangzhou, \\ China, ${ }^{3}$ Guangdong Province Translational Forensic Medicine Engineering Technology Research Center, Zhongshan School \\ of Medicine, Sun Yat-sen University, Guangzhou, China
}

OPEN ACCESS

Edited by:

Israel Liberzon,

University of Michigan Health System, United States

Reviewed by:

Piray Atsak,

Donders Institute for Brain, Cognition and Behaviour, Radboud University,

Netherlands

Rafael Roesler,

Universidade Federal do Rio Grande do Sul (UFRGS), Brazil

*Correspondence:

Li Xue xueli5@mail.sysu.edu.cn

Hu Zhao

zhaohu3@mail.sysu.edu.cn

tThese authors have contributed equally to this work

Received: 13 November 2018 Accepted: 18 February 2019 Published: 06 March 2019

Citation:

Liu X-H, Zhu R-T, Hao B, Shi Y-W, Wang $X-G$, Xue $L$ and Zhao $H$ (2019) Norepinephrine Induces PTSD-Like Memory Impairments via Regulation of the $\beta$-Adrenoceptor-CAMP/PKA and CaMK IIIPKC Systems in the

Basolateral Amygdala. Front. Behav. Neurosci. 13:43. doi: 10.3389/fnbeh.2019.00043
Glucocorticoids (GCs) can modulate the memory enhancement process during stressful events, and this modulation requires arousal-induced norepinephrine (NE) activation in the basolateral amygdale (BLA). Our previous study found that an intrahippocampal infusion of propranolol dose-dependently induced post-traumatic stress disorder (PTSD)-like memory impairments. To explore the role of the noradrenergic system of the BLA in PTSD-like memory impairment, we injected various doses of NE into the BLA. We found that only a specific quantity of NE $(0.3 \mu \mathrm{g})$ could induce PTSD-like memory impairments, accompanied by a reduction in phosphorylation of GluR1 at Ser845 and Ser831. Moreover, this phenomenon could be blocked by a protein kinase A (PKA) inhibitor or calcium/calmodulin-dependent protein kinase II (CaMK II) inhibitor. These findings demonstrate that NE could induce PTSD-like memory impairments via regulation of the $\beta$-adrenoceptor receptor ( $\beta$-AR)-3',5'-cyclic monophosphate (CAMP)/PKA and CaMK II/PKC signaling pathways.

Keywords: PTSD, fear conditioning, basolateral amygdala, norepinephrine, AMPA, cAMP/PKA, CaMK II/PKC

\section{INTRODUCTION}

Post-traumatic stress disorder (PTSD) is a serious anxiety disorder that usually follows a life-threatening traumatic event. The primary diagnostic criteria are re-experiencing of the trauma, autonomic reactivity to response, avoidance of trauma-related cues and elevated arousal (Long et al., 2013). A core symptom of PTSD is dysregulated fear response that is characterized by an over-generalization of fear and in tandem an inability to inhibit fear responses in the presence of safety (Jovanovic et al., 2012). Kaouane et al. (2012) developed an animal behavioral model that infusion of glucocorticoids (GCs) into the hippocampus in the predicting-context group conditioned with a high-intensity shock induced PTSD-like memory impairments, which were manifested as decreased freezing to the correct predictor and generalized fear responses to the cues that were normally not a relevant predictor of the threat. This animal model evaluates the ability of subjects to restrict fear responses to the appropriate predictor of a threatening stimulus, innovatively induced the core symptoms of PTSD; however, the neurobiological mechanisms underlying pathological PTSD-like memory impairment remain unclear. 
GCs, steroid hormones from the adrenal cortex during stressful events, can modulate the memory enhancement process following an inverted- $U$ shape dose-response relationship (Roozendaal, 2000; Sandi and Pinelo-Nava, 2007; Barsegyan et al., 2014; Deppermann et al., 2014; Finsterwald and Alberini, 2014). Additionally, this modulation requires arousal-induced norepinephrine (NE) activation in the basolateral amygdale (BLA; Roozendaal et al., 2004, 2006a,c), which is a key component of the neuronal circuits mediating emotional arousal and stress hormone effects on cognitive functions (McGaugh, 2004; Huff et al., 2006; Ehrlich et al., 2009; McIntyre et al., 2012). Evidence, including anatomical (Pikkarainen et al., 1999), behavioral (Roozendaal, 2000; Roozendaal et al., 2006c; McReynolds et al., 2010, 2014), electrophysiological (Akirav and Richter-Levin, 1999; Almaguer-Melian et al., 2003; Vouimba and Richter-Levin, 2013), and optogenetic data (Nabavi et al., 2014; Redondo et al., 2014; Tanaka et al., 2014; Rei et al., 2015), has shown that the amygdala modulates hippocampal memory storage. One of our recent studies found that an intrahippocampal infusion of propranolol dose-dependently induced PTSD-like memory impairments, demonstrating that the NE system in the hippocampus was involved in the formation of PTSD-like memory impairment (Zhu et al., 2018). However, whether NE within the BLA is a key factor in PTSD-like memory impairments remains unclear.

Numerous studies have demonstrated that NE activates adenosine $3^{\prime}, 5^{\prime}$-cyclic monophosphate (cAMP), cAMP-dependent protein kinase A (PKA; Roozendaal et al., 2002) and calcium/calmodulin-dependent protein kinase II (CaMK II) via $\beta$-adrenoceptor receptors ( $\beta$-ARs) in the emotional memory (Hu et al., 2007). In contrast, other findings have shown that PKA activation, but not CaMK II activation, in the BLA is critical for cocaine memory restabilization processes (Arguello et al., 2014). Therefore, whether NE activates the $\beta$-AR-cAMP/PKA or CaMK II/PKC signaling pathway in PTSD-like memory impairments within the BLA remains to be elucidated.

Simultaneously, NE acting through $\beta$-ARs has powerful effects on the induction of long-term potentiation (LTP), which is one type of synaptic plasticity that has been linked to memory storage (Roozendaal et al., 2006b; O'Dell et al., 2010). Synaptic insertion of GluR1 subunit-containing $\alpha$-amino3-hydroxy-5-methyl-4-isoxazoleproprionic acid (AMPA)-type receptors (AMPARs) appears to have a critical role in the synaptic strengthening observed during LTP induction (Lee et al., 2003; Hu et al., 2007). AMPARs are ionotropic glutamate receptors generated by the combination of four subunit proteins known as GluR1, GluR2, GluR3, and GluR4 (Traynelis et al., 2010). Prior findings showed that LTP was reduced in GluR1 gene inactivation mice and phosphomutant mice with knock-in mutations of the GluR1 phosphorylation sites (Jensen et al., 2003; Hu et al., 2007). Consequently, phosphorylation of AMPA receptor GluR1 subunits has a key role in $\beta$-AR-mediated enhancement of both LTP and behavioral learning. Furthermore, GluR1 subunits have many phosphorylation sites in the intracellular C-terminal domain; the central role of phosphorylation of Ser831 and Ser845 sites has been well elucidated. Ser831 is phosphorylated by PKC as well as other kinases such as CaMK II, whereas Ser845 is phosphorylated by PKA (Jensen et al., 2003; Hu et al., 2007; O'Dell et al., 2010, 2015). GluR1 Ser831 phosphorylation potentiates single-channel conductance (Derkach, 2003), and GluR1 Ser845 phosphorylation increases the channel open probability (Banke et al., 2000).

Thus, changes in GluR1 Ser845 and Ser831 phosphorylation provide an indicator of synaptic plasticity. The aim of this study was to investigate whether NE influenced PTSD-like memory impairments via regulation of the $\beta$-AR-cAMP/PKA or CaMK II/PKC signaling pathway. We also observed the phosphorylation changes of Ser845 and Ser831 in GluR1.

\section{MATERIALS AND METHODS}

\section{Subjects}

All male Sprague-Dawley rats (280-320 g) were purchased from the Experimental Animal Center at Sun Yat-sen University. Rats were individually on a 12-h light-dark cycle with ad libitum access to food and water. All behavioral experiments were performed during the light cycle between 9 AM and 3 PM. All procedures were approved by the Institutional Animal Care and Use Committee of the Zhongshan School of Medicine, Sun Yatsen University, in accordance with the National Institutes of Health Guide for the Care and Use of Laboratory Animals.

\section{Surgery}

The animals were adapted to the vivarium for at least 1 week before surgery. After each rat was fully anesthetized with sodium pentobarbital (50 mg/kg of body weight, i.p.), the skull was fixed to a stereotaxic frame (RWD, Shenzhen, China), and stainless-steel guide cannulas were implanted bilaterally with the cannula tips $2 \mathrm{~mm}$ above the BLA [coordinates: anteroposterior (AP), $-2.8 \mathrm{~mm}$ from Bregma; mediolateral (ML), $\pm 5.0 \mathrm{~mm}$ from midline; dorsoventral (DV), $-6.5 \mathrm{~mm}$ from skull surface] according to the atlas of Paxinos and Watson (2007). The cannulas and two anchoring screws were affixed to the skull with dental cement. Stylets were inserted into the cannulas to maintain patency and were removed only for the infusion of drugs. The animals were allowed to recover for a minimum of 7 days before training and were handled for 2 min per day during this recovery period to accustom them to the infusion procedures.

\section{Fear Conditioning}

After the handling days were completed, all rats were habituated in the acclimation chamber (Context A: an opaque PVC chamber, $\mathrm{W} \times \mathrm{L} \times \mathrm{H}: 30 \mathrm{~cm} \times 24 \mathrm{~cm} \times 21 \mathrm{~cm}$, an opaque PVC floor, a brightness of 100 lux) for 4 min without shock exposure. The acclimation chamber was also cleaned with $4 \%$ acetic acid before each trial. Two days later, animals were trained in a fear conditioning chamber (Context B: a transparent Plexiglas chamber, $\mathrm{W} \times \mathrm{L} \times \mathrm{H}: 28 \mathrm{~cm} \times 21 \mathrm{~cm} \times 22 \mathrm{~cm}$, a brightness of $60 \mathrm{lux}$ ) that contained a floor with 18 stainless steel rods and was connected to a shock generator and sound generator (Coulbourn Instruments, Allentown, PA, USA) developed inhouse. The conditioning chamber was also cleaned with $70 \%$ 
ethanol before each trial. During training, each rat was placed into context B. After $110 \mathrm{~s}$ of free exploration, the rat was exposed to two footshocks (1.4 mA, 110 intertrial interval) that lasted for $3 \mathrm{~s}$. After a $20 \mathrm{~s}$ delay, the rat received two tone cues $(65 \mathrm{~dB}$, $1 \mathrm{kHz}, 30 \mathrm{~s}$ intertrial interval) that lasted for $15 \mathrm{~s}$. After $20 \mathrm{~s}$, the animals were placed back into its home cage. Twenty-four hours later, animals were tested in context A with cue trials (65 dB, $1 \mathrm{kHz}, 2 \mathrm{kHz}$, or white noise) alone for $2 \mathrm{~min}$. Two hours later, they were retested in context B for 2 min without the cues. Control groups were habituated to the training apparatus. The shock intensity (1.4 mA) was selected based on previous experiments conducted in our laboratory. In this case, animals will identify the conditioning context but not the cue as the right predictor of the shock. Freezing behavior was analyzed with a software program (Graphic State, Coulbourn Instruments, Allentown, PA, USA).

\section{Drug and Infusion Procedures}

All drug solutions were freshly prepared on the experimental days. For the first experiment, the nonspecific $\beta$-AR antagonist DL-propranolol $(0.5 \mu \mathrm{g} / 0.2 \mu \mathrm{l}$ per hemisphere; Sigma Aldrich, St. Louis, MO, USA) either alone or together with NE $(0.3 \mu \mathrm{g} / 0.2 \mu \mathrm{l}$ per hemisphere; Sigma Aldrich, St. Louis, MO, USA) was dissolved in $0.9 \%$ saline and administered into the BLA immediately after conditioning with $1.4 \mathrm{~mA}$. For the second experiment, different doses of NE $(0.1,0.3$ or $1.0 \mu \mathrm{g} / 0.2 \mu \mathrm{l}$ per hemisphere; Sigma Aldrich) were dissolved in $0.9 \%$ saline and administered into the BLA immediately after conditioning with $1.4 \mathrm{~mA}$. These doses were selected on the basis of previous research (Quirarte et al., 1997; Banke et al., 2000; Barsegyan et al., 2014). For the last experiment, the selective PKA inhibitor Rp-cAMPS (4.0 $\mu \mathrm{g} / 0.2 \mu \mathrm{l}$ per hemisphere; Sigma Aldrich, St. Louis, MO, USA) or the selective CaMK II inhibitor KN-93 (5.0 $\mu \mathrm{g} / 0.5 \mu \mathrm{l}$ per hemisphere; Sigma Aldrich, St. Louis, MO, USA) was dissolved in saline and infused into the BLA $10 \mathrm{~min}$ before fear conditioning training. NE $(0.3 \mu \mathrm{g} / 0.2 \mu \mathrm{l}$ per hemisphere) was administered to the BLA immediately after conditioning with $1.4 \mathrm{~mA}$. These doses were selected on the basis of previous research (Roozendaal et al., 2002; Arguello et al., 2014).

In each experiment, the injection needle protruded $2 \mathrm{~mm}$ beyond the tip of the cannulas, and a $0.2 \mu \mathrm{l}$ or $0.5 \mu \mathrm{l}$ injection volume was infused over a period of $1 \mathrm{~min}$ by an automated syringe pump CMA402 (CMA Microdialysis BA, Solna, Sweden). All drug solutions were prepared freshly before each experiment, and the infusion procedures used were identical to those described above. The injection cannulas were left in place for 1 min after drug infusion to maximize diffusion and to prevent backflow of the drug into the cannulas.

\section{Western Blot Analysis}

After rats were sacrificed, brains were immediately frozen, and the BLA was microdissected using a $1 \mathrm{~mm}$ section rat brain matrix and frozen in liquid nitrogen prior to storage at $-80^{\circ} \mathrm{C}$. The supernatant was then assayed for total protein concentration using the BCA Protein Assay Kit. Tissue homogenate samples were resolved in $8 \%$ SDS-polyacrylamide gels, blotted electrophoretically onto PVDF membranes, blocked at room temperature for $1 \mathrm{~h}$ in PBS buffer containing 5\% nonfat milk, and then blotted overnight at $4^{\circ} \mathrm{C}$ with antibodies to GluR1 (1:1,000; Millipore, Temecula, CA, USA), phosphorylated GluR1 at Ser831 and Ser845 (1:1,000; Millipore), and GAPDH (1/1,000; Cell Signaling Technology, Danvers, MA, USA). Then, the membranes were incubated with HRP-conjugated secondary antibody for $1 \mathrm{~h}$. The densitometric analysis of Western blot was performed using a ChemiDoc XRS system (Bio-Rad, Hercules, CA, USA), and data analysis was performed by Image Lab version 5.2.1 (Bio-Rad, Hercules, CA, USA).

\section{Histology}

After the testing sessions, each rat was deeply anesthetized with a moderate dose of sodium pentobarbital and transcardially perfused with $0.9 \%$ saline, followed by $4 \%$ paraformaldehyde. The animal was then decapitated, and its brain was removed from the skull and placed in 4\% paraformaldehyde. After 7 days, the brains were sliced at $40 \mu \mathrm{m}$ thickness and stained with thionin. The sites of microinjections were verified according to the atlas of Paxinos and Watson (2007). Rats with injection needle placements outside the BLA or with extensive tissue damage at the injection needle tips were excluded from analysis.

\section{Data Analysis}

All data are expressed as the mean \pm SEM. One-way ANOVA (post hoc Fisher's least significant difference) and two-way ANOVA with Fisher's PLSD post hoc tests were used when appropriate. Analyses were conducted using SPSS 20.0 software. $P<0.05$ was chosen as the criterion for statistical significance.

\section{RESULTS}

\section{Histology}

Figure 1 illustrates the schematic (part A) and actual (part B) results of the corresponding sections taken from the rat brain atlas of Paxinos and Watson (2007).

\section{Intra-BLA Infusion of NE Induced Dose-Dependent PTSD-Like Memory Impairments}

In Experiment 1, we first tested whether NE-induced effects within the BLA had a similar dose-dependent effect as the GC-induced effects on PTSD-like memory impairment, we tested the effects of NE immediately after conditioning by microinfusing different doses $(0.1,0.3$, and $1.0 \mu \mathrm{g})$ into the BLA of rats administered the high-intensity shock. As shown in Figure 2A, one-way ANOVA indicated that the 0.3 and $1.0 \mu \mathrm{g}$ $\mathrm{NE}$ groups both showed impaired contextual fear conditioning, and the $0.1 \mu \mathrm{g}$ NE group showed enhanced contextual and cue fear conditioning (context: $F_{(3,18)}=18.476, P<0.001$; cue: $\left.F_{(3,18)}=14.929, P<0.001\right)$. Fisher's post hoc analysis confirmed that the 0.3 and $1.0 \mu \mathrm{g}$ NE groups exhibited significantly decreased freezing time in the contextual memory retention test $(0.3 \mu \mathrm{g}$ NE: $P<0.001 ; 1.0 \mu \mathrm{g}$ NE: $P<0.001)$. Fisher's post hoc analysis also revealed that the $0.1 \mu \mathrm{g}$ and $0.3 \mu \mathrm{g}$ NE groups exhibited significantly increased freezing time in the contextual memory retention test $(0.1 \mu \mathrm{g}$ NE: $P=0.001$; 
A

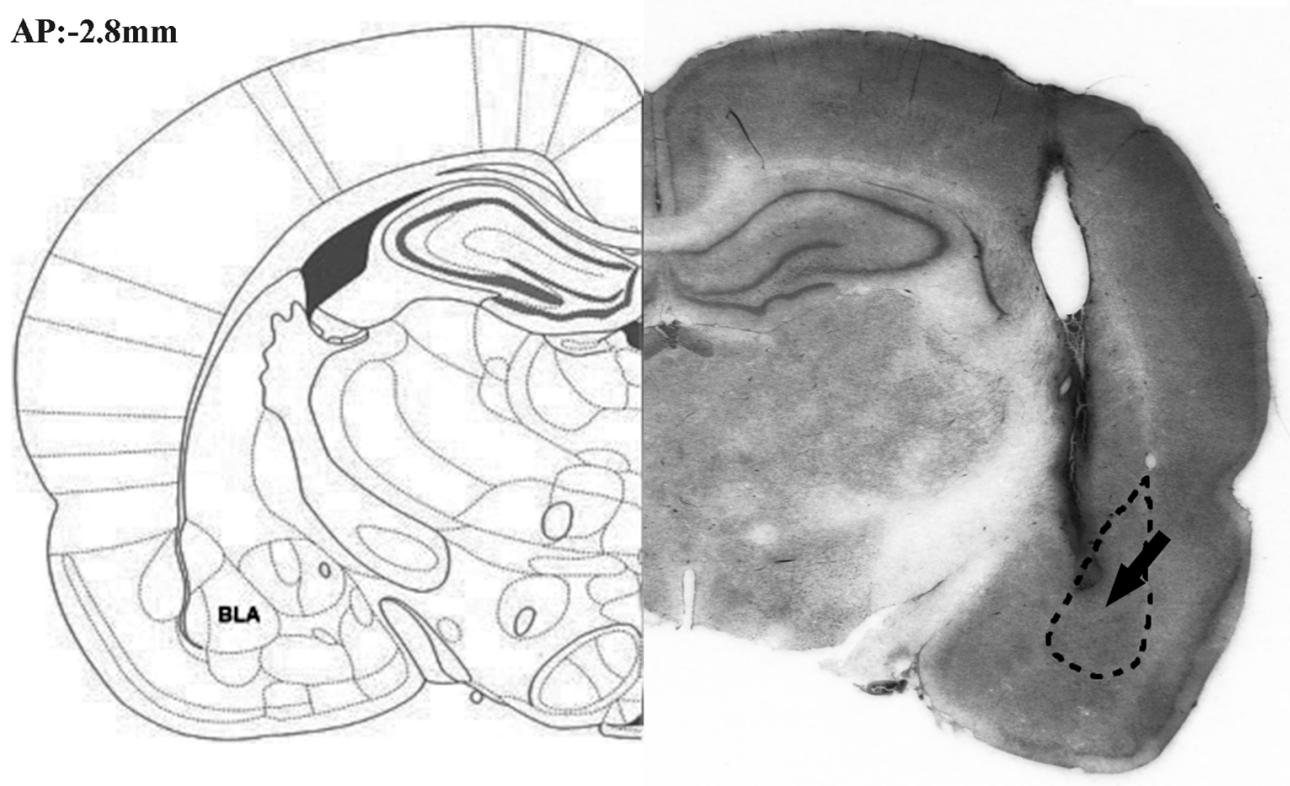

FIGURE 1 | Representative photomicrograph illustrating the location of microinjection into the basolateral amygdale (BLA). The schematic (part A) and actual (part B) results on corresponding section taken from the rat brain atlas of Paxinos and Watson (2007), arrow points to needle tip.

$0.3 \mu \mathrm{g}$ NE: $P<0.001)$. We found that 0.3 and $1.0 \mu \mathrm{g} \mathrm{NE}$ can both impair contextual fear conditioning, and thus, we tested the generalization of fear responses to different cues. Only the $0.3 \mu \mathrm{g}$ NE group of rats exhibited generalization of fear responses to different cues, as enhanced $1 \mathrm{kHz}$ and $2 \mathrm{kHz}$ cue fear conditioning was observed $\left(F_{(2,11)}=37.485\right.$, $P<0.001$; Figure 2B).

Then, to investigate whether the effects of NE on memory was mediated by beta receptors or not, effective dose of NE with or without propranolol was microinfused into the BLA immediately after conditioning with a high-intensity shock $(1.4 \mathrm{~mA})$. As shown in Figure 2C, one-way ANOVA indicated that rats in the NE and propranolol groups both had impaired contextual fear conditioning; however, the $\mathrm{NE}+$ propranolol groups showed enhanced contextual and cue fear memories (context: $F_{(3,17)}=6.882, P=0.003$; cue: $\left.F_{(3,17)}=13.459, P<0.001\right)$. Fisher's post hoc analysis confirmed that the NE and propranolol groups exhibited significantly decreased freezing time in the contextual memory retention test (NE: $P=0.008$; propranolol: $P=0.008)$. Meanwhile, Fisher's post hoc analysis also revealed that the propranolol and NE + propranolol groups exhibited significantly increased freezing time in the cue memory retention test (propranolol: $P<0.001$; NE + propranolol: $P=0.006$ ). Interestingly, when $\mathrm{NE}$ and propranolol were simultaneously injected into the BLA immediately after conditioning with the high-intensity shock $(1.4 \mathrm{~mA})$, freezing time increased in the contextual and cue memories retention test, indicating that this treatment enhanced contextual and cue fear memories.

Altogether, these results indicated that $\mathrm{NE}$ has a dose-dependent effect on PTSD-like memory impairments and that only the moderate dose $(0.3 \mu \mathrm{g})$ of NE could induce PTSD-like memory impairments.

\section{NE Induced PTSD-Like Memory Impairments via Downregulation of AMPA Receptor Phosphorylation}

$\mathrm{NE}$ is mediated by mechanisms involving activation of $\beta$-ARs in the BLA, and the $\beta$-AR is directly linked to AMPAR functional modulation and trafficking to synaptic sites. GluR1 Ser831 and Ser845 phosphorylation sites have been proposed to play a key role in AMPAR trafficking and synaptic plasticity. GluR1 Ser831 is phosphorylated by PKC as well as other kinases, such as CaMK II, whereas Ser845 is phosphorylated by PKA. To further characterize the signaling events that lead to NE-induced PTSD-like memory impairments, we observed the phosphorylation changes of Ser845 and Ser831 in GluR1. As shown in Figure 3A, Ser831 phosphorylation of GluR1 was decreased in the NE and propranolol groups but was increased in the $\mathrm{NE}+$ propranolol group of rats (GluR1 Ser831: $F_{(3,12)}=21.291, P<0.001$; NE, $P=0.023$; propranolol, $P=0.003$; $\mathrm{NE}+$ propranolol, $P=0.004$, LSD-t after one-way ANOVA). Ser845 phosphorylation of GluR1 was decreased in the NE and propranolol groups but was increased in the NE + propranolol group of rats (GluR1 Ser845: $F_{(3,12)}=28.524, P<0.001$; NE, $P=0.036$; propranolol, $P=0.001 ; \mathrm{NE}+$ propranolol, $P=0.001$, LSD-t after one-way ANOVA). However, GluR1 was not altered in these three groups $\left(F_{(3,12)}=0.337, P=0.779\right.$, one-way ANOVA).

Meanwhile, as shown in Figure 3B, Ser831 phosphorylation of GluR1 was decreased in the $0.3 \mu \mathrm{g}$ and $1.0 \mu \mathrm{g}$ NE groups 

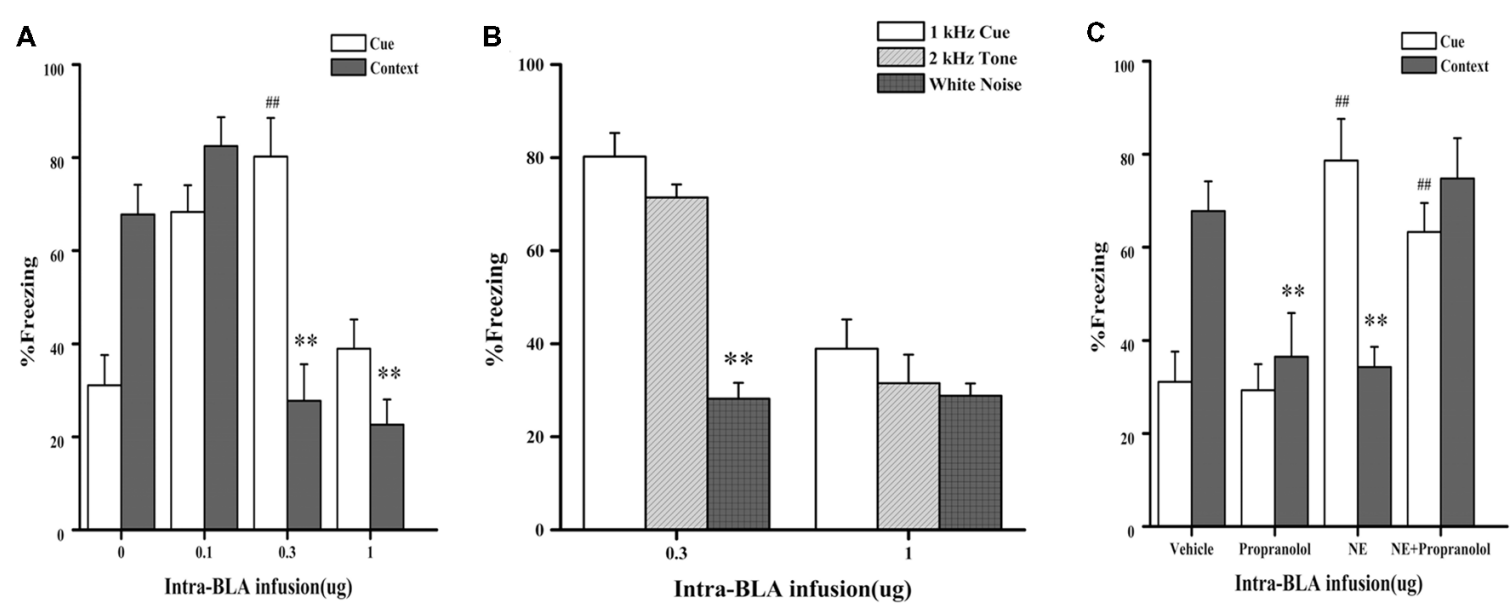

FIGURE 2 | Intra-BLA infusion of norepinephrine (NE) induced a dose-dependent post-traumatic stress disorder (PTSD)-like memory impairments. (A) NE $(0.3 \mu \mathrm{g} / 0.2 \mu \mathrm{l})$ administered into the BLA immediately after fear conditioning impaired retention of contextual fear memory and enhanced retention of cue fear memory. Concurrent infusion of $\beta$-adrenoceptor ( $\beta$-AR) antagonist DL-propranolol ( $0.5 \mu \mathrm{g} / 0.2 \mu \mathrm{l})$ blocked this NE-induced memory impairments. Results represent mean \pm SEM. ${ }^{* *} P<0.01,{ }^{\# \#} P<0.01$ compared with vehicle. (B) NE $(0.1,0.3$, or $1.0 \mu \mathrm{g} / 0.2 \mu \mathrm{l})$ administered into the BLA immediately after fear conditioning dose-dependent impaired retention of contextual fear memory. Results represent mean \pm SEM. ${ }^{* *} P<0.01,{ }^{\# \#} P<0.01$ compared with vehicle. (C) NE $(0.3 \mu \mathrm{g} / 0.2 \mu \mathrm{l})$ induced PTSD-like memory impairments, which increased the response to $2 \mathrm{kHz}$ tone but not to white noise. Results represent mean \pm SEM. ** $P<0.01$ vs. $1 \mathrm{kHz}$ cue.

but increased in the $0.1 \mu \mathrm{g}$ NE group $\left(F_{(3,12)}=27.479\right.$, $P<0.001 ; 0.1 \mu \mathrm{g} \mathrm{NE}, P=0.003 ; 0.3 \mu \mathrm{g} \mathrm{NE}, P=0.003$; $1.0 \mu \mathrm{g} \mathrm{NE}, P=0.001$, LSD-t after one-way ANOVA). Ser845 phosphorylation of GluR1 was decreased in the $0.3 \mu \mathrm{g}$ NE group $\left(F_{(3,12)}=27.838, P<0.001 ; 0.3 \mu \mathrm{g}\right.$ NE, $P<0.001$, LSD-t after one-way ANOVA). GluR1 was not altered in these three groups $\left(F_{(3,12)}=0.59, P=0.633\right.$, one-way ANOVA). Thus, phosphorylation of both Ser845 and Ser831 was decreased in the NE-induced PTSD-like memory impairment.

\section{NE Induced PTSD-Like Memory Impairments via Regulation of the cAMP/PKA and CaMK/PKC Signaling \\ Pathways}

As mentioned above, NE induces PTSD-like memory impairments along with decreased Ser845 and Ser831 phosphorylation of GluR1. Ser831 is phosphorylated by PKC as well as other kinases, such as CaMK II, whereas Ser845 is phosphorylated by PKA. Thus, to determine whether administration of NE within the BLA can activate the cAMP/PKA or CaMK II/PKC signaling pathway in PTSD-like memory impairments, we inhibited the cAMP/PKA or CaMK II/PKC pathway. As shown in Figures 4Aa,b, intra-BLA infusion of the PKA inhibitor Rp-cAMPS $(4.0 \mu \mathrm{g}) 10 \mathrm{~min}$ before fear conditioning blocked PTSD-like memory impairments induced by immediate post-training intra-BLA infusions of NE. The two-way ANOVA for percent freezing time during the contextual and cue memory retention test revealed a significant PKA inhibitor effect in the contextual memory retention test (context: $F_{(1,22)}=0.758, P=0.395$; cue: $F_{(1,22)}=12.541$, $P=0.002$ ), a significant effect of NE in the contextual and cue memory retention test (context: $F_{(1,22)}=0.020, P=0.890$; cue: $F_{1,22}=19.605, P<0.001$ ), and a significant interaction between these two factors in the contextual and cue memory retention test (context: $F_{(1,22)}=25.607, P<0.001 ; F_{(1,22)}=11.988$, $P=0.003)$. Rp-cAMPS not only induced contextual memory retention impairment when administered alone but also blocked PTSD-like memory impairments induced by immediate post-training intra-BLA infusion of NE (context: $F_{(3,19)}=8.533$, $P=0.001$; saline $+\mathrm{NE}$ vs. Rp-cAMPS $+\mathrm{NE}, P=0.005$, LSD-t after one-way ANOVA; cue: $F_{(3,19)}=15.15, P<0.001$; saline + NE vs. Rp-cAMPS + NE, $P<0.001$, LSD-t after one-way ANOVA).

Meanwhile, as shown in Figures $4 \mathbf{B a}, \mathbf{b}$, intra-BLA infusion of the CaMK II inhibitor KN-93 $(0.5 \mu \mathrm{g}) 10 \mathrm{~min}$ before fear conditioning blocked PTSD-like memory impairments induced by immediate post-training intra-BLA infusions of NE. The two-way ANOVA for percent freezing time during the contextual and cue memory retention test revealed a significant CaMK II inhibitor effect in contextual memory retention test (context: $F_{(1,24)}=3.036, P=0.096$; cue: KN-93: $F_{(1,24)}=21.788$, $P<0.001)$, a significant effect of $\mathrm{NE}$ in the contextual and cue memory retention test (context: NE: $F_{(1,24)}=4.727$, $P=0.041$; cue: $\left.F_{(1,24)}=14.160, P=0.001\right)$, and a significant interaction between these two factors in the contextual and cue memory retention test (context: $F_{(1,24)}=8.535, P=0.008$; $\left.F_{(1,24)}=19.372, P<0.001\right)$. KN-93 not only induced contextual memory retention impairment when administered alone but also blocked PTSD-like memory impairments induced by immediate post-training intra-BLA infusion of NE (context: $F_{(3,21)}=4.708, P=0.011$; saline $+\mathrm{NE}$ vs. $\mathrm{KN}-93+\mathrm{NE}$, $P=0.386$, LSD-t after one-way ANOVA; cue: $F_{(3,21)}=18.786$, $P<0.001$; saline + NE vs. KN-93 + NE, $P<0.001$, LSD-t after one-way ANOVA). 

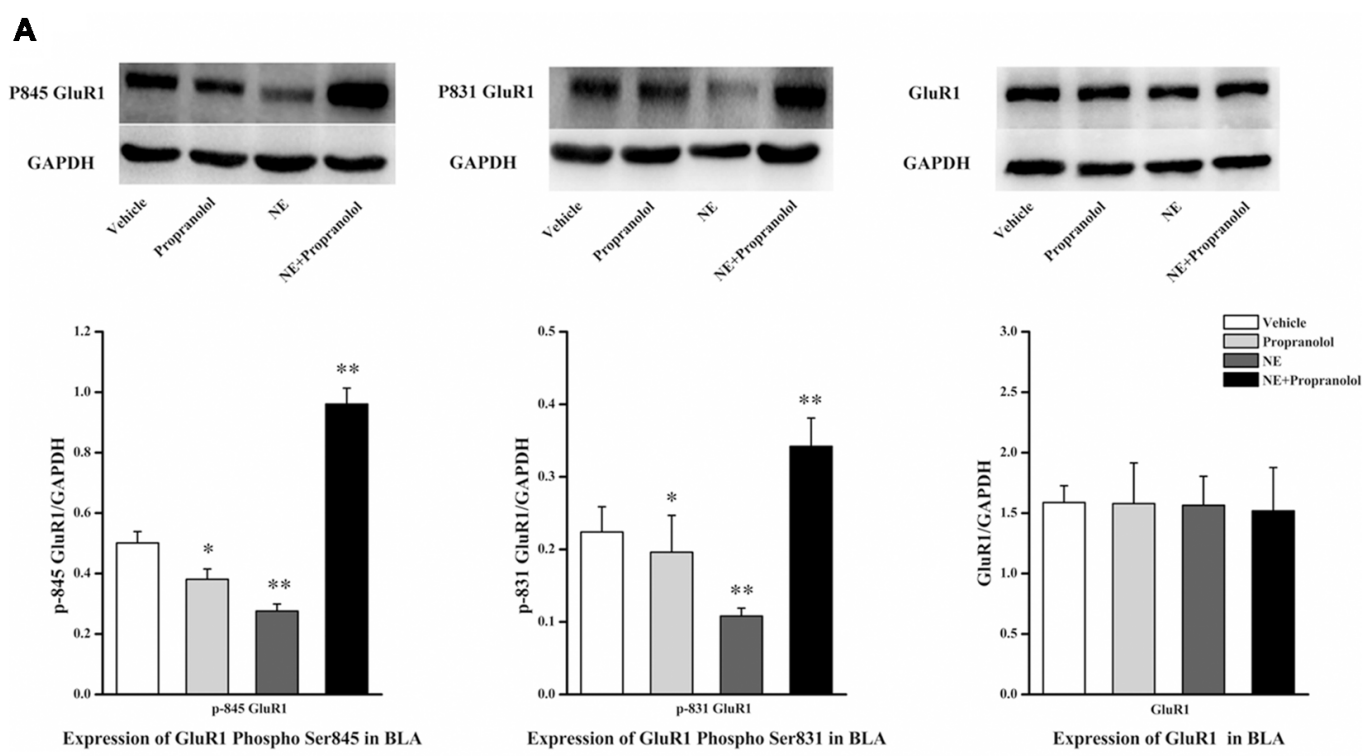

B

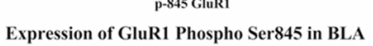

Expression of GluR1 in BLA
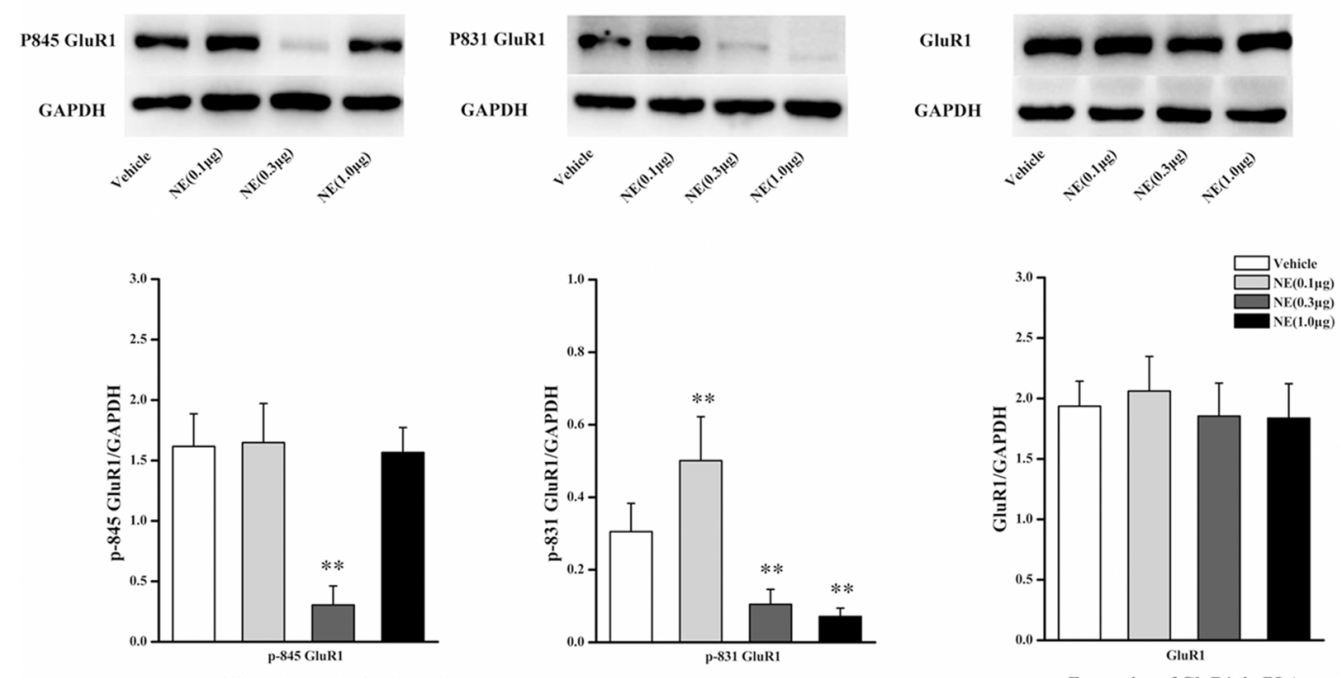

Expression of GluR1 Phospho Ser831 in BLA

FIGURE 3 | NE induced PTSD-like memory impairments via down-regulation the expression of Ser845 and Ser831 phosphorylation of GluR1. (A) Representative immunoblots showing the effect of the bilateral intra-BLA infusion of NE $(0.3 \mu \mathrm{g} / 0.2 \mu \mathrm{l})$ or propranolol $(5 \mu \mathrm{g} / 0.2 \mu \mathrm{l})$ immediately after fear conditioning induced change in phospho-GluR1 and total GluR1 levels. (B) Representative immunoblots showing the effect of the bilateral intra-BLA infusion of NE with the different doses of NE $(0.1,0.3$, or $1.0 \mu \mathrm{g} / 0.2 \mu \mathrm{l})$ immediately after training induced change in phospho-GluR1 and total GluR1 levels. All results represent mean $\pm \mathrm{SEM}$. ${ }^{*} P<0.05$, ${ }^{* *} P<0.01$, vs. vehicle group.

We next tested the effect of inhibition of the cAMP/PKA or CaMK II/PKC signaling pathway in PTSD-like memory impairments on the phosphorylation changes of Ser845 and Ser831 of GluR1. We found that Ser831 phosphorylation of GluR1 was decreased in the saline + NE and Rp-cAMPS + vehicle groups (GluR1 Ser831: $F_{(3,12)}=3.69, P=0.043$; saline + NE, $P=0.011 ;$ Rp-cAMPS + vehicle, $P=0.026$, LSD-t after one-way ANOVA; Figure 5A). Ser845 phosphorylation of GluR1 was decreased in the saline + NE and Rp-cAMPS + vehicle groups (GluR1 Ser845: $F_{(3,12)}=9.73, P=0.002$; saline $+\mathrm{NE}$, $P=0.002 ;$ Rp-cAMPS + vehicle, $P=0.011$, LSD-t after one-way
ANOVA). However, GluR1 was not altered in these three groups $\left(F_{(3,12)}=0.302, P=0.823\right.$, one-way ANOVA $)$.

Additionally, Ser831 phosphorylation of GluR1 was decreased in the saline + NE, KN-93 + vehicle and KN-93 $+\mathrm{NE}$ groups compared with the saline + vehicle group (GluR1 Ser831: $F_{(3,12)}=4.879, P=0.019 ;$ saline $+\mathrm{NE}$, $P=0.008 ; \mathrm{KN}-93+$ vehicle, $P=0.005 ; \mathrm{KN}-93+\mathrm{NE}$, $P=0.030$, LSD-t after one-way ANOVA; Figure 5B). Ser845 phosphorylation of GluR1 was decreased in the saline $+\mathrm{NE}$ and $\mathrm{KN}-93+$ vehicle groups $\left(\right.$ GluR1 $F_{(3,12)}=12.465$, $P=0.001 ;$ saline + NE, $P<0.001 ; \mathrm{KN}-93+$ vehicle, $P=0.003$, 


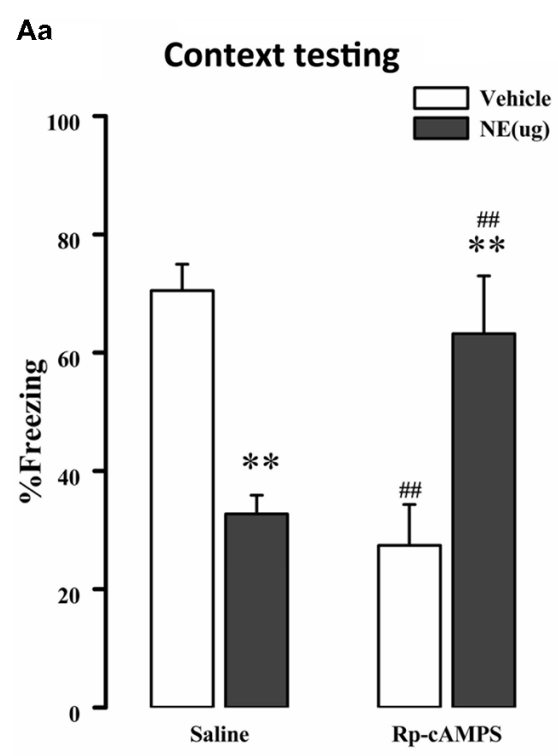

Intra-BLA infusion(ug)

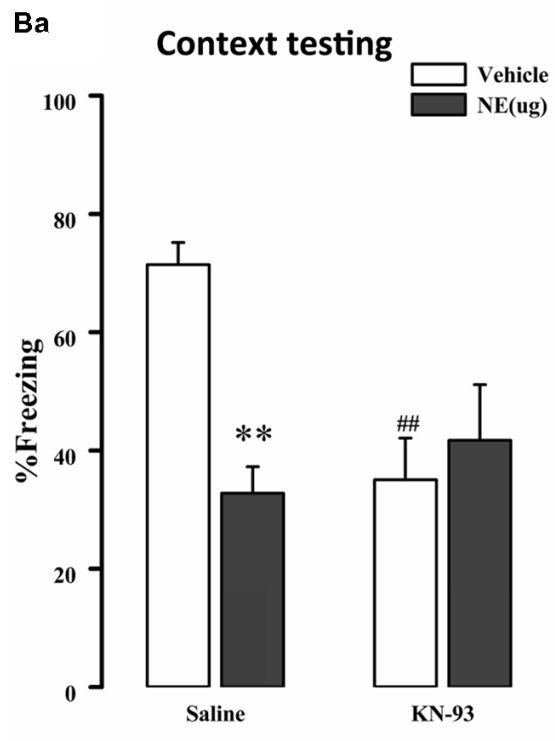

Intra-BLA infusion(ug)
$\mathbf{A b}$

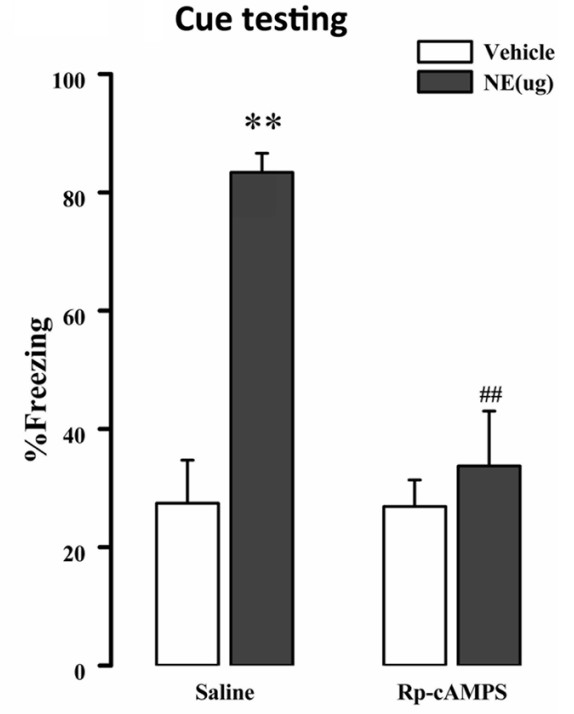

Intra-BLA infusion(ug)

$\mathrm{Bb}$

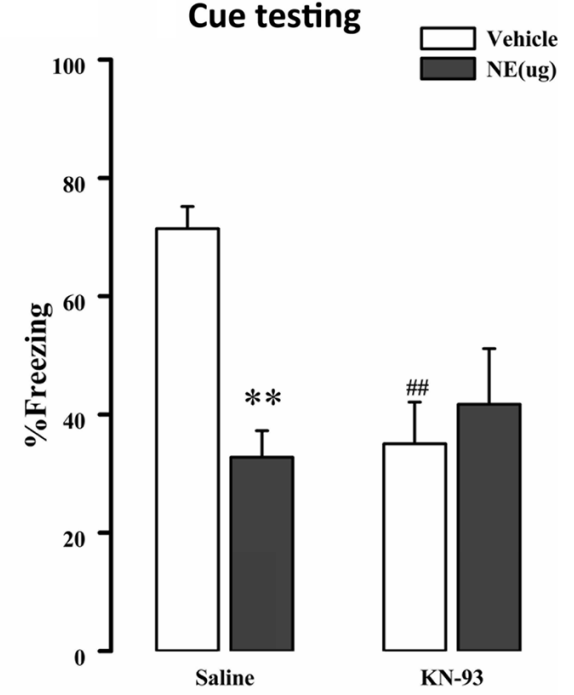

Intra-BLA infusion(ug)

FIGURE 4 | NE induced PTSD-like memory impairments via regulation 3',5'-cyclic monophosphate (cAMP)/protein kinase A (PKA) and calcium/calmodulin-dependent protein kinase II (CaMK II)/PKC signal pathway. (A) The PKA inhibitor Rp-cAMPS (4.0 $\mu \mathrm{g} / 0.2 \mu \mathrm{I})$ administered into the BLA $10 \mathrm{~min}$ before fear conditioning blocked the impairments of retention of contextual (Aa) and cue (Ab) fear memory induced by immediately post-training intra-BLA infusions of NE $(0.3 \mu \mathrm{g} / 0.2 \mu \mathrm{l})$. (B) The CaMKII inhibitor KN-93 $(5.0 \mu \mathrm{g} / 0.5 \mu \mathrm{l})$ administered into the BLA 10 min before fear conditioning also blocked the impairments of retention of contextual $\mathbf{( B a )}$ and cue $\mathbf{( B b})$ fear memory induced by immediately post-training intra-BLA infusions of NE $(0.3 \mu \mathrm{g} / 0.2 \mu \mathrm{l})$. All results represent mean \pm SEM. ${ }^{* *} P<0.01$ compared with the corresponding vehicle group, ${ }^{\# \#} P<0.01$ compared with the corresponding saline group.

LSD-t after one-way ANOVA). However, GluR1 was not altered in these three groups $\left(F_{(3,12)}=0.067, P=0.977\right.$, one-way ANOVA).

Together, these results showed that intra-BLA infusion of KN-93 $(0.5 \mu \mathrm{g})$ or Rp-cAMPS $(4.0 \mu \mathrm{g}) 10 \mathrm{~min}$ before fear conditioning can block PTSD-like memory impairments induced by immediate post-training intra-BLA infusions of NE, which can also lead to phosphorylation changes in the Ser845 and Ser831 sites of GluR1.

\section{DISCUSSION}

In PTSD patients, a core symptom is an excessive generalization of fear; patients show a strong response not only to a previous 


\section{A}

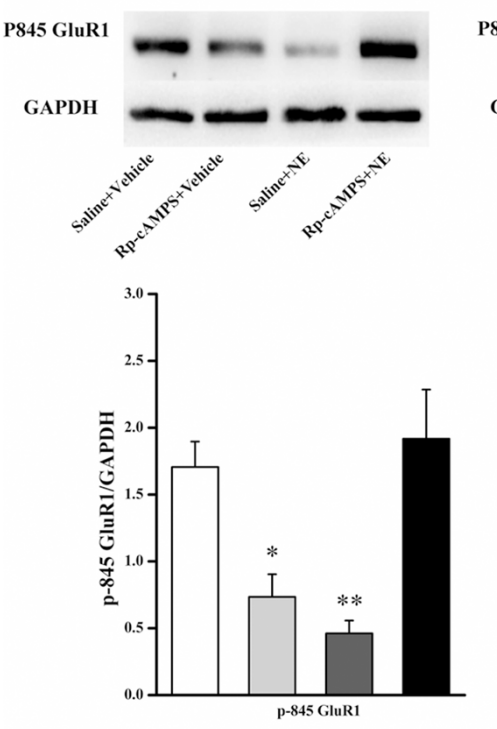

Expression of GluR1 Phospho Ser845 in BLA
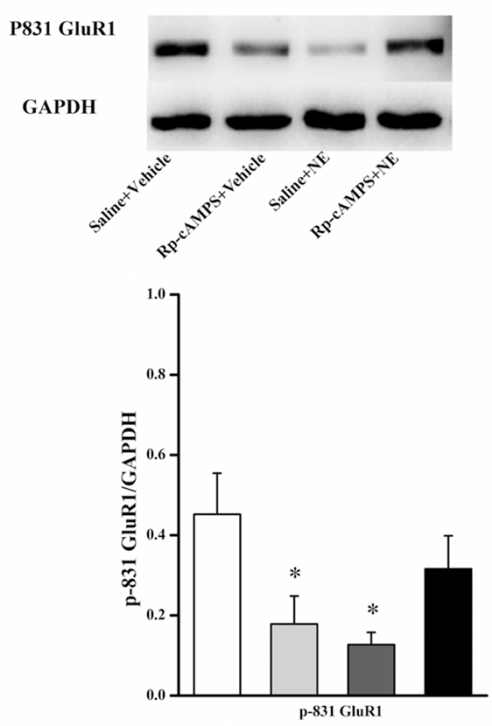

Expression of GluR1 Phospho Ser831 in BLA

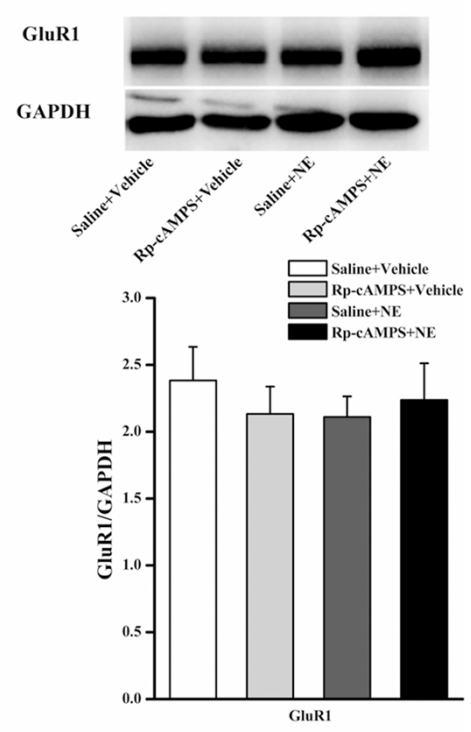

Expression of GluR1 in BLA

B
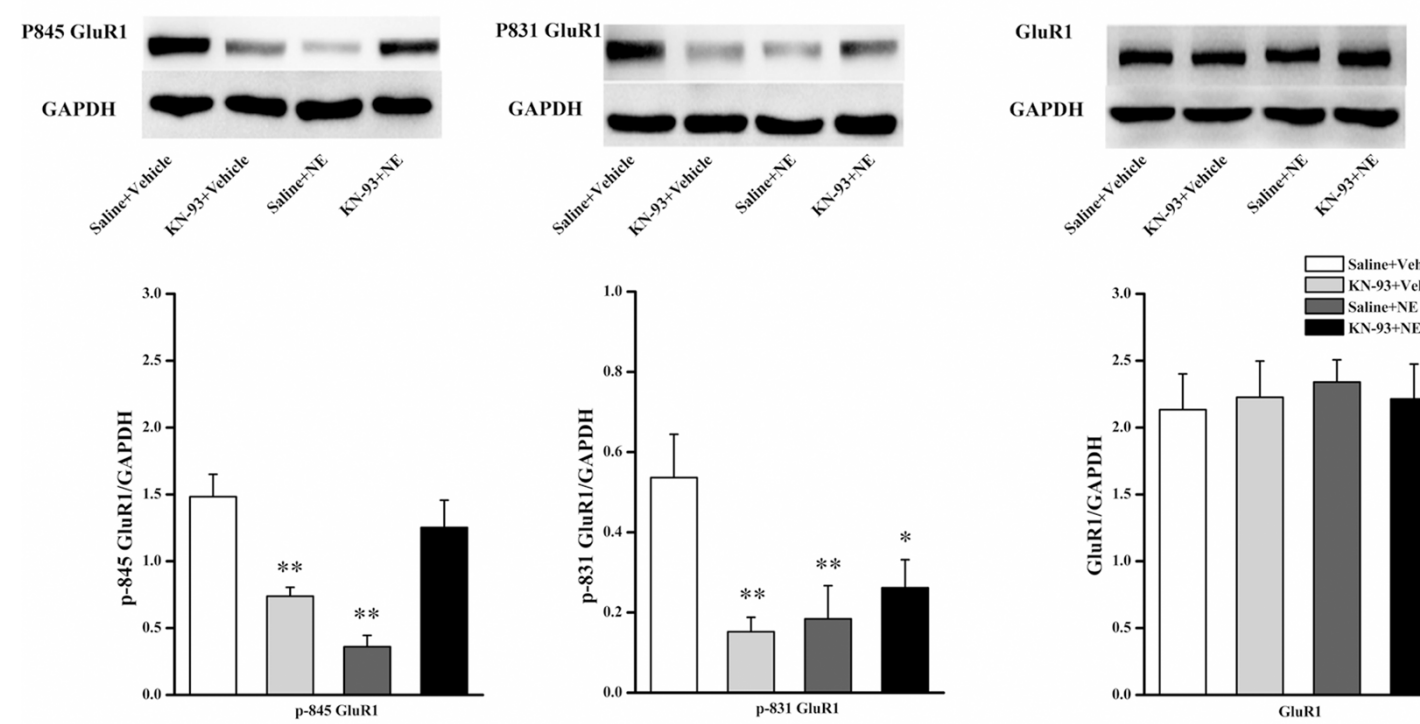

Expression of GluR1 Phospho Ser831 in BLA

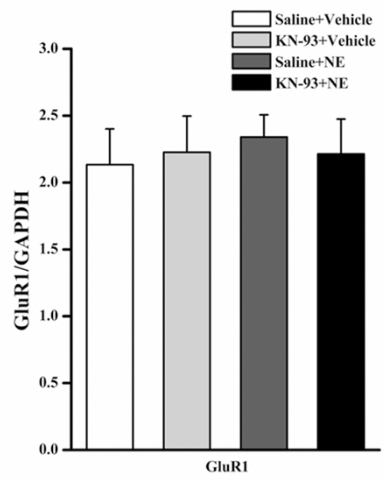

Expression of GluR1 in BLA

FIGURE 5 | Inhibition cAMP/PKA or CaMK II /PKC signal pathway can down-regulate the expression of Ser845 and Ser831 phosphorylation of GluR1. Representative immunoblots showing the effect of the bilateral intra-BLA infusion of Rp-cAMPS (4.0 $\mu \mathrm{g} / 0.2 \mu \mathrm{l}$; A) or KN-93 $(5.0 \mu \mathrm{g} / 0.5 \mu$; B B) 10 min before fear conditioning induced change in phospho-GluR1 and total GluR1 levels. All results represent mean \pm SEM. ${ }^{*} P<0.05,{ }^{* *} P<0.01$, vs. vehicle group.

learned fearful cue but also cues that signal safety. This memory disturbances for the core traumatic event and peritraumatic cues, contributes to the intrusive recollection of traumatic event. In this study, we investigated whether NE was a key factor in such PTSD-like memory impairments, as well as the possible neurobiological mechanism. Researcher interest in this issue stems from recent reports showing that GCs could induce PTSD-like memory impairments (Kaouane et al.,
2012). This animal model of PTSD-like memory impairment enables us to evaluate the ability of the individuals to restrict fear responses to the appropriate predictor of the threatening stimulus, instead of simply observe the freezing response to context or cue.

Evidence showed that GCs rely on NE activation in the BLA to affect memory consolidation (Banke et al., 2000; Roozendaal et al., 2006c). In this study, we found that 
only $0.3 \mu \mathrm{g}$ NE microinfused into the BLA immediately after fear conditioning could induce PTSD-like memory impairments and simultaneously reduce GluR1 Ser845 and Ser831 phosphorylation. Furthermore, NE had a dose-dependent effect similar to that of GCs on PTSD-like memory impairments. We also found that intra-BLA infusion of a PKA inhibitor or CaMK II inhibitor before fear conditioning could block PTSD-like memory impairments induced by immediate post-training intra-BLA infusions of NE. Therefore, our findings suggested that the BLA noradrenergic system is involved in mediating PTSD-like memory impairments via regulation of the $\beta$-AR-cAMP/PKA and CaMK II/PKC signaling pathways.

Numerous studies using different experimental paradigms have shown that the amygdala is a key brain structure in modulation of the stress response and fear memory (Ehrlich et al., 2009; Hermans et al., 2014; Aubry et al., 2016). Emotionally arousing experiences are known to be associated with elevated levels of NE (Hatfield et al., 1999; McGaugh and Roozendaal, 2002), and BLA is a critical site of NE action (Roozendaal et al., 2008; Mueller and Cahill, 2010). We found that the $\beta$-AR antagonist propranolol or NE microinfused into the BLA immediately after fear conditioning could impair contextual and cue fear memory, which is consistent with previous evidence (Bush et al., 2010; Barsegyan et al., 2014; Zhou et al., 2015). Interestingly, when NE and propranolol were injected together into the BLA immediately after fear conditioning, contextual and cue fear memory was enhanced, one possible reason is that a low dose of propranolol only partly blocked the effect of NE-induced memory impairments. Because higher intensity of noradrenergic transmission required higher doses of the $\beta$-ARs antagonist than other tasks (Debiec and Ledoux, 2004). Another possibility is the involvement of $\alpha_{2}$-adrenoceptor. The $\alpha_{2}$ adrenoceptor is predominantly located on presynaptic noradrenergic terminals and its activation inhibits NE release (Langer, 1974; Talley et al., 1996). Ferry and McGaugh (2008) showed that post-training intra-BLA infusions of a selective $\alpha_{2}$ adrenoceptor agonist induced a dose-dependent impairment of retention of inhibitory avoidance. While the $\mathrm{NE}$ release onto $\beta-\mathrm{AR}$ is required for induction and maintenance of LTP (Roozendaal et al., 2006b; O'Dell et al., 2010), leading to retention enhancement. Further study using particularly $\beta$-ARs agonists is needed to clarify this issue.

Furthermore, we found that NE had a dose-dependent effect on PTSD-like memory impairments, and only a moderate dose of NE could induce PTSD-like memory impairments-low doses of NE enhanced contextual and cue fear memories, and high doses of NE impaired contextual fear memory. These findings are consistent with previous evidence showing that NE produced dose-dependent enhancement or impairment of memory in other experimental paradigms (Roozendaal et al., 2008; Li et al., 2011). NE or a $\beta$-ARs agonist infused into the BLA immediately post-training enhances the retention of emotionally arousing training experiences (Barsegyan et al., 2014), by regulating neural plasticity and information storage processes in other brain regions, including hippocampus (Atucha et al., 2017). However, direct effect of NE infusion into the hippocampus seems controversial. Atsak et al. (2012) indicated that post-training $\mathrm{NE}$ infusions into the dorsal hippocampus during retention of auditory fear conditioning has no significant effect on fear response. Our previous work (Zhu et al., 2018) suggested that intra-hippocampus infusion of propranolol, not NE, dose-dependently induced PTSD-like memory impairments. In addition, the PTSD-like memory impairment model used in this study can be regarded as the impairment of memory accuracy. Our results suggested that post-training NE infusions into the BLA decrease the accuracy of the fear memory, inconsistent with some others. This discrepancy may prominently due to our different experimental design. For example, Barsegyan et al. (2014) employed an object-in-context recognition memory design, had no emotional arousing in their study. Additionally, there are two factors in this fear conditioning, including context and cue, but only context in Atucha' work (Atucha et al., 2017), and BLA is known for its crucial effect in cue fear memory. Moreover, the footshock in this work is $1.4 \mathrm{~mA}$, much stronger than $0.6 \mathrm{~mA}$ they used, may induce more release of stress hormones, including GC, NE, etc. Moreover, another interesting finding is that the enhancement of irrelative cue retention performed earlier than impairment of context memory as the dose increases. It has long been known that BLA is crucially involved in the formation of cue fear memory (Ehrlich et al., 2009), thus changes may first show in cue memory. Since the memory specificity impaired after $\mathrm{NE}$ infusion, animals could not restrict fear responses to the appropriate predictor-context, but present higher freezing in cue test. NE regulates synaptic plasticity and glutamatergic excitatory post-synaptic currents (EPSCs; Almaguer-Melian et al., 2005; Walling et al., 2016) through several pathways that are regulated by phosphorylation of the AMPARs (Esteban et al., 2003; Oh et al., 2006). GluR1 Ser831 and Ser845 phosphorylation sites have been proposed to play a key role in AMPAR trafficking and synaptic plasticity. Moreover, prior findings indicated that NE signaling induces phosphorylation of the Ser845 and Ser831 sites of GluR1 in the emotional regulation of learning and memory (Banke et al., 2000; Derkach, 2003; Hu et al., 2007). However, how this regulation occurs in PTSD-like memory impairments is unknown. Our results showed that Ser831 and Ser845 phosphorylation of GluR1 was decreased by post-training intra-BLA infusions of $0.3 \mu \mathrm{g} \mathrm{NE}$, and the phosphorylation decrease at the Ser831 or Ser845 site was driven by $\beta$-AR inhibition and infusion of high doses of NE, while phosphorylation increased at low doses, which was consistent with behavioral experiments indicating that there is an association between NE and AMPAR signaling pathways in the regulation of GluR1 Ser831 and Ser845 phosphorylation. This finding reveals that NE induces PTSD-like memory impairments via downregulation of AMPA receptor phosphorylation. In other words, this finding provides a potential explanation for the regulation of AMPA receptor trafficking and might offer a potentially beneficial treatment for PTSD.

It is well established that signaling molecules such as PKA, mitogen-activated protein kinase (MAPK), $\mathrm{Ca}^{2+} / \mathrm{CaMKII}$ have also been implicated in the maintenance of LTP and 
consolidation of fear memory in the amygdala (Toyoda et al., 2011). Indeed, cAMP/PKA signaling plays a critical role in presynaptically expressed LTP (Castillo et al., 2002; Young and Thomas, 2014). Increased PKA activity leads to phosphorylation of GluR1 on Ser845, increasing the channel open probability (Banke et al., 2000). While the increased CaMKII activity leads to phosphorylation of Ser831, potentiating single-channel conductance (Derkach, 2003). Furthermore, we found that intra-BLA infusion of KN-93 or Rp-cAMPS 10 min before fear conditioning blocked PTSD-like memory impairments induced by immediate post-training intra-BLA infusions of NE. This finding provided direct evidence for NE-induced PTSD-like memory impairments via regulation of the cAMP/PKA and CaMK II/PKC signaling pathways. Simultaneously, we also found Ser831 and Ser845 phosphorylation of GluR1 decreased due to pre-training intra-BLA infusions of the PKA inhibitor or CaMK II inhibitor alone. However, Ser831 and Ser845 phosphorylation of GluR1 was not significantly changed by pre-training intra-BLA infusions of Rp-cAMPS and post-training infusions of NE. These findings indicated that $\mathrm{NE}$ activation of $\beta$-ARs enhances behavioral memory via the cAMP/PKA and CaMK II/PKC signaling pathways (Hu et al., 2007; Zhou et al., 2013). However, besides activates PKA and CaMK II, other molecules including NMDA receptor, has been suggested to be the downstream targets of NE (Huang et al., 1993; Raman et al., 1996), which preferentially couple to phosphatases

\section{REFERENCES}

Akirav, I., and Richter-Levin, G. (1999). Biphasic modulation of hippocampal plasticity by behavioral stress and basolateral amygdala stimulation in the rat. J. Neurosci. 19, 10530-10535. doi: 10.1523/JNEUROSCI.19-2310530.1999

Almaguer-Melian, W., Martínez-Martí, L., Frey, J. U., and Bergado, J. A. (2003). The amygdala is part of the behavioural reinforcement system modulating long-term potentiation in rat hippocampus. Neuroscience 119, 319-322. doi: 10.1016/s0306-4522(02)00867-9

Almaguer-Melian, W., Rojas-Reyes, Y., Alvare, A., Rosillo, J. C., Frey, J. U., and Bergado, J. A. (2005). Long-term potentiation in the dentate gyrus in freely moving rats is reinforced by intraventricular application of norepinephrine, but not oxotremorine. Neurobiol. Learn. Mem. 83, 72-78. doi: 10.1016/j.nlm.2004. 08.002

Arguello, A. A., Hodges, M. A., Wells, A. M., Lara, H. III., Xie, X., and Fuchs, R. A. (2014). Involvement of amygdalar protein kinase A, but not calcium/calmodulin-dependent protein kinase II, in the reconsolidation of cocaine-related contextual memories in rats. Psychopharmacology 231, 55-65. doi: 10.1007/s00213-013-3203-9

Atsak, P., Hauer, D., Campolongo, P., Schelling, G., McGaugh, J. L., and Roozendaal, B. (2012). Glucocorticoids interact with the hippocampal endocannabinoid system in impairing retrieval of contextual fear memory. Proc. Natl. Acad. Sci. U S A 109, 3504-3509. doi: 10.1073/pnas.1200742109

Atucha, E., Vukojevic, V., Fornari, R. V., Ronzoni, G., Demougin, P., Peter, F., et al. (2017). Noradrenergic activation of the basolateral amygdala maintains hippocampus-dependent accuracy of remote memory. Proc. Natl. Acad. Sci. U S A 114, 9176-9181. doi: 10.1073/pnas.1710819114

Aubry, A. V., Serrano, P. A., and Burghardt, N. S. (2016). Molecular mechanisms of stress-induced increases in fear memory consolidation within the amygdala. Front. Behav. Neurosci. 10:191. doi: 10.3389/fnbeh.2016.00191

Banke, T. G., Bowie, D., Lee, H. K., Huganir, R. L., Schousboe, A., and Traynelis, S. F. (2000). Control of GluR1 AMPA receptor function by cAMP-dependent protein kinase. J. Neurosci. 20, 89-102. doi: 10.1523/JNEUROSCI.20-01-00089.2000 at lower levels of activation while activating kinases at higher levels. Vanhoose and Winder (2003) reported that a saturating dose of NMDA induces dephosphorylation of Ser845. Therefore, the changes in phosphorylation levels found in this study may be caused by a combination of factors. In future studies, it will be necessary to determine whether NMDAR involved in the modulation of NE induced PTSD-like memory impairment.

In conclusion, our findings reveal that $\mathrm{NE}$ regulates the $\beta$-ARcAMP/PKA and CaMK II/PKC signaling pathways, leading to PTSD-like memory impairments.

\section{AUTHOR CONTRIBUTIONS}

HZ and LX contributed to the conception of the work. X-HL and R-TZ designed and collected the data. X-HL, R-TZ, BH, Y-WS and X-GW collected and analyzed the data. XL wrote the article. All authors discussed the results and commented on the manuscript. All authors approved the final version of the manuscript.

\section{FUNDING}

This research was supported by the National Natural Science Foundation of China $(81471829 ; 81530061 ; 81772032)$ and the National Science Foundation for Young Scientists of China (81601652).

Barsegyan, A., McGaugh, J. L., and Roozendaal, B. (2014). Noradrenergic activation of the basolateral amygdala modulates the consolidation of object-incontext recognition memory. Front. Behav. Neurosci. 8:160. doi: 10.3389/fnbeh. 2014.00160

Bush, D. E. A., Caparosa, E. M., Gekker, A., and LeDoux, J. (2010). $\beta$-adrenergic receptors in the lateral nucleus of the amygdala contribute to the acquisition but not the consolidation of auditory fear conditioning. Front. Behav. Neurosci. 4:154. doi: 10.3389/fnbeh.2010.00154

Castillo, P. E., Schoch, S., Schmitz, F., Sudhof, T. C., and Malenka, R. C. (2002). RIM1 $\alpha$ is required for presynaptic long-term potentiation. Nature 415 , 327-330. doi: 10.1038/415327a

Debiec, J., and Ledoux, J. E. (2004). Disruption of reconsolidation but not consolidation of auditory fear conditioning by noradrenergic blockade in the amygdala. Neuroscience 129, 267-272. doi: 10.1016/j.neuroscience.2004.08.018

Deppermann, S., Storchak, H., Fallgatter, A. J., and Ehlis, A. C. (2014). Stressinduced neuroplasticity: (mal) adaptation to adverse life events in patients with PTSD_a critical overview. Neuroscience 283, 166-177. doi: 10.1016/j. neuroscience.2014.08.037

Derkach, V. A. (2003). Silence analysis of AMPA receptor mutated at the CaM-kinase II phosphorylation site. Biophys. J. 84, 1701-1708. doi: 10.1016/s0006-3495(03)74978-9

Ehrlich, I., Humeau, Y., Grenier, F., Ciocchi, S., Herry, C., and Lüthi, A. (2009). Amygdala inhibitory circuits and the control of fear memory. Neuron 62, 757-771. doi: 10.1016/j.neuron.2009.05.026

Esteban, J. A., Shi, S. H., Wilson, C., Nuriya, M., Huganir, R. L., and Malinow, R. (2003). PKA phosphorylation of AMPA receptor subunits controls synaptic trafficking underlying plasticity. Nat. Neurosci. 6, 136-143. doi: 10.1038/ nn997

Ferry, B., and McGaugh, J. L. (2008). Involvement of basolateral amygdala $\alpha 2$-adrenoceptors in modulating consolidation of inhibitory avoidance memory. Learn. Mem. 15, 238-243. doi: 10.1101/lm.760908

Finsterwald, C., and Alberini, C. M. (2014). Stress and glucocorticoid receptordependent mechanisms in long-term memory: from adaptive responses to psychopathologies. Neurobiol. Learn. Mem. 112, 17-29. doi: 10.1016/j.nlm. 2013.09.017 
Hatfield, T., Spanis, C., and McGaugh, J. L. (1999). Response of amygdalar norepinephrine to footshock and GABAergic drugs using in vivo microdialysis and HPLC. Brain Res. 835, 340-345. doi: 10.1016/s0006-8993(99) 01566-8

Hermans, E. J., Battaglia, F. P., Atsak, P., de Voogd, L. D., Fernandez, G., and Roozendaal, B. (2014). How the amygdala affects emotional memory by altering brain network properties. Neurobiol. Learn. Mem. 112, 2-16. doi: 10.1016/j. nlm.2014.02.005

Hu, H., Real, E., Takamiya, K., Kang, M. G., Ledoux, J., Huganir, R. L., et al. (2007). Emotion enhances learning via norepinephrine regulation of AMPA-receptor trafficking. Cell 131, 160-173. doi: 10.1016/j.cell.2007.09.017

Huang, C. C., Tsai, J. J., and Gean, P. W. (1993). Enhancement of NMDA receptormediated synaptic potential by isoproterenol is blocked by Rp-adenosine 3', 5'cyclic monophosphothioate. Neurosci. Lett. 161, 207-210. doi: 10.1016/03043940(93)90295-v

Huff, N. C., Frank, M., Wright-Hardesty, K., Sprunger, D., MatusAmat, P., Higgins, E., et al. (2006). Amygdala regulation of immediateearly gene expression in the hippocampus induced by contextual fear conditioning. J. Neurosci. 26, 1616-1623. doi: 10.1523/JNEUROSCI.496405.2006

Jensen, V., Kaiser, K. M. M., Borchardt, T., Adelmann, G., Rozov, A., Burnashev, N., et al. (2003). A juvenile form of postsynaptic hippocampal long-term potentiation in mice deficient for the AMPA receptor subunit GluR-A. J. Physiol. 553, 843-856. doi: 10.1113/jphysiol.2003. 053637

Jovanovic, T., Kazama, A., Bachevalier, J., and Davis, M. (2012). Impaired safety signal learning may be a biomarker of PTSD. Neuropharmacology 62, 695-704. doi: 10.1016/j.neuropharm.2011.02.023

Kaouane, N., Porte, Y., Vallee, M., Brayda-Bruno, L., Mons, N., Calandreau, L., et al. (2012). Glucocorticoids can induce PTSD-like memory impairments in mice. Science 335, 1510-1513. doi: 10.3410/f.14256989.15768132

Langer, S. Z. (1974). Presynaptic regulation of catecholamine release. Biochem. Pharmacol. 23, 1793-1800. doi: 10.1016/0006-2952(74)90187-7

Lee, H. K., Takamiya, K., Han, J. S., Man, H., Kim, C. H., Rumbaugh, G., et al. (2003). Phosphorylation of the AMPA receptor GluR1 subunit is required for synaptic plasticity and retention of spatial memory. Cell 112, 631-643. doi: 10.1016/s0092-8674(03)00122-3

Li, Q., Liu, X., Zeng, Q., Xue, Q., Cao, X., Liu, J., et al. (2011). Post-training intrabasolateral amygdala infusions of norepinephrine block sevoflurane-induced impairment of memory consolidation and activity-regulated cytoskeletal protein expression inhibition in rat hippocampus. Neurobiol. Learn. Mem. 96, 492-497. doi: 10.1016/j.nlm.2011.08.002

Long, Z., Duan, X., Xie, B., Du, H., Li, R., Xu, Q., et al. (2013). Altered brain structural connectivity in post-traumatic stress disorder: a diffusion tensor imaging tractography study. J. Affect. Disord. 150, 798-806. doi: 10.1016/j.jad. 2013.03.004

McGaugh, J. L. (2004). The amygdala modulates the consolidation of memories of emotionally arousing experiences. Annu. Rev. Neurosci. 27, 1-28. doi: 10.1146/annurev.neuro.27.070203.144157

McGaugh, J. L., and Roozendaal, B. (2002). Role of adrenal stress hormones in forming lasting memories in the brain. Curr. Opin. Neurobiol. 12, 205-210. doi: 10.1016/s0959-4388(02)00306-9

McIntyre, C. K., McGaugh, J. L., and Williams, C. L. (2012). Interacting brain systems modulate memory consolidation. Neurosci. Biobehav. Rev. 36, 1750-1762. doi: 10.1016/j.neubiorev.2011.11.001

McReynolds, J. R., Anderson, K. M., Donowho, K. M., and McIntyre, C. K. (2014). Noradrenergic actions in the basolateral complex of the amygdala modulate Arc expression in hippocampal synapses and consolidation of aversive and non-aversive memory. Neurobiol. Learn. Mem. 115, 49-57. doi: 10.1016/j.nlm. 2014.08.016

McReynolds, J. R., Donowho, K., Abdi, A., McGaugh, J. L., Roozendaal, B., and McIntyre, C. K. (2010). Memory-enhancing corticosterone treatment increases amygdala norepinephrine and Arc protein expression in hippocampal synaptic fractions. Neurobiol. Learn. Mem. 93, 312-321. doi: 10.1016/j.nlm.2009. 11.005

Mueller, D., and Cahill, S. P. (2010). Noradrenergic modulation of extinction learning and exposure therapy. Behav. Brain Res. 208, 1-11. doi: 10.1016/j.bbr. 2009.11.025
Nabavi, S., Fox, R., Proulx, C. D., Lin, J. Y., Tsien, R. Y., and Malinow, R. (2014). Engineering a memory with LTD and LTP. Nature 511, 348-352. doi: 10.1038/nature13294

O’Dell, T. J., Connor, S. A., Gelinas, J. N., and Nguyen, P. V. (2010). Viagra for your synapses: enhancement of hippocampal long-term potentiation by activation of $\beta$-adrenergic receptors. Cell. Signal. 22, 728-736. doi: 10.1016/j.cellsig.2009. 12.004

O’Dell, T. J., Connor, S. A., Guglietta, R., and Nguyen, P. V. (2015). $\beta$ adrenergic receptor signaling and modulation of long-term potentiation in the mammalian hippocampus. Learn. Mem. 22, 461-471. doi: 10.1101/lm. 031088.113

Oh, M. C., Derkach, V. A., Guire, E. S., and Soderling, T. R. (2006). Extrasynaptic membrane trafficking regulated by GluR1 serine 845 phosphorylation primes AMPA receptors for long-term potentiation. J. Biol. Chem. 281, 752-758. doi: 10.1074/jbc.M509677200

Paxinos, G., and Watson, C. (2007). The Rat Brain in Stereotaxic Coordinates. Boston: Academic Press.

Pikkarainen, M., Rönkkö, S., Savander, V., Insausti, R., and Pitkänen, A. (1999). Projections from the lateral, basal and accessory basal nuclei of the amygdala to the hippocampal formation in rat. J. Comp. Neurol. 403, 229-260. doi: 10.1002/(sici)1096-9861(19990111)403:2<229::aid-cne7>3.0.co;2-p

Quirarte, G. L., Roozendaal, B., and McGaugh, J. L. (1997). Glucocorticoid enhancement of memory storage involves noradrenergic activation in the basolateral amygdala. Proc. Natl. Acad. Sci. U S A 94, 14048-14053. doi: 10.1073/pnas.94.25.14048

Raman, I. M., Tong, G., and Jahr, C. E. (1996). $\beta$-adrenergic regulation of synaptic NMDA receptors by cAMP-dependent protein kinase. Neuron 16, 415-421. doi: 10.1016/s0896-6273(00)80059-8

Redondo, R. L., Kim, J., Arons, A. L., Ramirez, S., Liu, X., and Tonegawa, S. (2014). Bidirectional switch of the valence associated with a hippocampal contextual memory engram. Nature 513, 426-430. doi: 10.1038/nature 13725

Rei, D., Mason, X., Seo, J., Gräff, J., Rudenko, A., Wang, J., et al. (2015). Basolateral amygdala bidirectionally modulates stress-induced hippocampal learning and memory deficits through a p25/Cdk5-dependent pathway. Proc. Natl. Acad. Sci. US A 112, 7291-7296. doi: 10.1073/pnas.1415845112

Roozendaal, B. (2000). Glucocorticoids and the regulation of memory consolidation. Psychoneuroendocrinology 25, 213-238. doi: 10.1016/s03064530(99)00058-x

Roozendaal, B., Castello, N. A., Vedana, G., Barsegyan, A., and McGaugh, J. L. (2008). Noradrenergic activation of the basolateral amygdala modulates consolidation of object recognition memory. Neurobiol. Learn. Mem. 90, 576-579. doi: 10.1016/j.nlm.2008.06.010

Roozendaal, B., McReynolds, J. R., and McGaugh, J. L. (2004). The basolateral amygdala interacts with the medial prefrontal cortex in regulating glucocorticoid effects on working memory impairment. J. Neurosci. 24, 1385-1392. doi: 10.1523/JNEUROSCI.4664-03.2004

Roozendaal, B., Hui, G., Hui, I., Berlau, D., McGaugh, J., and Weinberger, N. (2006a). Basolateral amygdala noradrenergic activity mediates corticosteroneinduced enhancement of auditory fear conditioning. Neurobiol. Learn. Mem. 86, 249-255. doi: 10.1016/j.nlm.2006.03.003

Roozendaal, B., Okuda, S., de Quervain, D. J. F., and McGaugh, J. L. (2006b). Glucocorticoids interact with emotion-induced noradrenergic activation in influencing different memory functions. Neuroscience 138, 901-910. doi: 10.1016/j.neuroscience.2005.07.049

Roozendaal, B., Okuda, S., Van der Zee, E. A., and McGaugh, J. L. (2006c). Glucocorticoid enhancement of memory requires arousal-induced noradrenergic activation in the basolateral amygdala. Proc. Natl. Acad. Sci. US A 103, 6741-6746. doi: 10.1073/pnas.0601874103

Roozendaal, B., Quirarte, G. L., and McGaugh, J. L. (2002). Glucocorticoids interact with the basolateral amygdala $\beta$-adrenoceptor-cAMP/cAMP/PKA system in influencing memory consolidation. Eur. J. Neurosci. 15, 553-560. doi: 10.1046/j.0953-816x.2001.01876.x

Sandi, C., and Pinelo-Nava, M. T. (2007). Stress and memory: behavioral effects and neurobiological mechanisms. Neural Plast. 2007:78970. doi: 10.1155/2007/78970

Talley, E. M., Rosin, D. L., Lee, A., Guyenet, P. G., and Lynch, K. R. (1996). Distribution of $\alpha_{2}$-adrenergic receptor-like immunoreactivity in the rat central 
nervous system. J. Comp. Neurol. 372, 111-134. doi: 10.1002/(SICI)10969861(19960812)372:1<111::AID-CNE8>3.0.CO;2-6

Tanaka, K. Z., Pevzner, A., Hamidi, A. B., Nakazawa, Y., Graham, J., and Wiltgen, B. J. (2014). Cortical representations are reinstated by the hippocampus during memory retrieval. Neuron 84, 347-354. doi: 10.1016/j. neuron.2014.09.037

Toyoda, H., Li, X. Y., Wu, L. J., Zhao, M. G., Descalzi, G., Chen, T., et al. (2011). Interplay of amygdala and cingulate plasticity in emotional fear. Neural Plast. 2011:813749. doi: 10.1155/2011/813749

Traynelis, S. F., Wollmuth, L. P., McBain, C. J., Menniti, F. S., Vance, K. M., Ogden, K. K., et al. (2010). Glutamate receptor ion channels: structure, regulation and function. Pharmacol. Rev. 62, 405-496. doi: 10.1124/pr.109. 002451

Vanhoose, A. M., and Winder, D. G. (2003). NMDA and $\beta 1$-adrenergic receptors differentially signal phosphorylation of glutamate receptor type 1 in area CA1 of hippocampus. J. Neurosci. 23, 5827-5834. doi: 10.1523/jneurosci.2313-05827.2003

Vouimba, R., and Richter-Levin, G. (2013). Different patterns of amygdala priming differentially affect dentate gyrus plasticity and corticosterone, but not CA1 plasticity. Front. Neural Circuits 7:80. doi: 10.3389/fncir.2013. 00080

Walling, S. G., Milway, J. S., Ingram, M., Lau, C., Morrison, G., and Martin, G. M. (2016). The effects of prolonged administration of norepinephrine reuptake inhibitors on long-term potentiation in dentate gyrus and on tests of spatial and object recognition memory in rats. Neurobiol. Learn. Mem. 128, 92-102. doi: $10.1016 /$ j.nlm.2015.12.013
Young, M. B., and Thomas, S. A. (2014). M1-muscarinic receptors promote fear memory consolidation via phospholipase C and the M-current. J. Neurosci. 34, 1570-1578. doi: 10.1523/JNEUROSCI.1040-13.2014

Zhou, J., Luo, Y., Zhang, J., Li, M., Wang, C., Guan, X., et al. (2015). Propranolol decreases retention of fear memory by modulating the stability of surface glutamate receptor GluA1 subunits in the lateral amygdala. Brit. J. Pharmacol. 172, 5068-5082. doi: 10.1111/bph.13272

Zhou, H. C., Sun, Y. Y., Cai, W., He, X. T., Yi, F., Li, B. M., et al. (2013). Activation of $\beta 2$-adrenoceptor enhances synaptic potentiation and behavioral memory via cAMP-PKA signaling in the medial prefrontal cortex of rats. Learn. Mem. 20, 274-284. doi: 10.1101/lm.030411.113

Zhu, R. T., Liu, X. H., Shi, Y. W., Wang, X. G., Xue, L., and Zhao, H. (2018). Propranolol can induce PTSD-like memory impairments in rats. Brain Behav. 8:e00905. doi: 10.1002/brb3.905

Conflict of Interest Statement: The authors declare that the research was conducted in the absence of any commercial or financial relationships that could be construed as a potential conflict of interest.

Copyright (c) 2019 Liu, Zhu, Hao, Shi, Wang, Xue and Zhao. This is an open-access article distributed under the terms of the Creative Commons Attribution License (CC BY). The use, distribution or reproduction in other forums is permitted, provided the original author(s) and the copyright owner(s) are credited and that the original publication in this journal is cited, in accordance with accepted academic practice. No use, distribution or reproduction is permitted which does not comply with these terms. 